\title{
Química mineral, cristalização e deformação de granitos sintectônicos brasilianos da região de Arrozal, SW do Rio de Janeiro
}

\author{
Alexis Rosa Nummer ${ }^{1}$, Luis Antônio Rosa Seixas ${ }^{2}$ \& Rômulo Machado ${ }^{3}$
}

\begin{abstract}
Resumo Este trabalho apresenta dados de análises de química mineral de feldspatos (feldspato alcalino e plagioclásio) e biotita de granitos sintectônicos da região de Arrozal, porção sudoeste do Estado do Rio de Janeiro, envolvendo fácies deformadas e não deformadas dos Maciços Graníticos Arrozal (MGA) e Getulândia (MGG) e amostra da rocha encaixante. São maciços graníticos alongados na direção ENE-WSW e associados a zonas de cisalhamento de alto ângulo do vale do Rio Paraíba do Sul. Possuem foliação magmática na parte central e de deformação no estado sólido nas bordas. Do MGA foram analisadas três faciologias: (i) Porfirítica (central), (ii) Foliada (borda), (iii) Leucogranítica. Do MGG foram analisadas duas faciologias: (i) Inequigranular e (ii) Equigranular foliada. A composição do feldspato alcalino situa-se próximo ao pólo do ortoclásio no diagrama $\mathrm{Or}-\mathrm{Ab}-\mathrm{Na}$; a do plagioclásio é albítico (fácies leucogranítica) e andesina (fácies porfirítica, foliada e enclave). A biotita do MGA é mais férrica ( $\mathrm{Fe} \#$ entre 0,5 a 0,8 ) e aluminosa ( 17 a $19 \% \mathrm{de}_{2} \mathrm{Al}_{2} \mathrm{O}_{3}$ ), situando-se entre os pólos da annita e siderofilita; a biotita do MGG é mais magnesiana ( $\mathrm{Fe} \# \sim 0,5)$ e menos aluminosa (14 a $15 \%$ de $\mathrm{Al}_{2} \mathrm{O}_{3}$ ), e situa-se entre os pólos da flogopita e eastonita ( $\mathrm{Fe} \#$ entre 0,5 e 0,8 ). As biotitas estudadas são preferencialmente primárias e foram pouco afetadas pela deformação no estado sólido. As biotitas da fácies foliada do MGA, em relação às das demais fácies do maciço, possuem conteúdos semelhantes em $\mathrm{Mg} 0 \mathrm{e} \mathrm{Ti} 0_{2}$, porém mais elevados em $\mathrm{Al}_{2} \mathrm{O}_{3}$.
\end{abstract}

Palavras-chave: Zonas de Cisalhamento, Granito Arrozal, Química Mineral, Cálcico-alcalino.

\begin{abstract}
Mineral chemistry, crystallization and deformation of the Brazilian syntectonic granites of Arrozal region, $S W$ of the Rio de Janeiro. This paper presents mineral chemistry of feldspars (Alkali-feldspar and plagioclase) and biotite of the brazilian syntectonic granites of the Arrozal region, southwestern of the State of Rio de Janeiro, envolving deformated e not deformated facies of the Arrozal (AGM) and Getulândia (GGM) Granitic Massifs and sample of their host rocks. Three facies of the first massif were analysed: (i) porphyritic, (ii) foliated, (iii) leucogranitic; and two facies of the second massif: (i) inequigranular and (ii) equigranular. The composition of alkaline feldspar is situated near the orthoclase pole in the Or-Ab-Na diagram. The composition of plagioclase is albite (leucogranitic facies) and andesine (porphyritic, foliated and enclave). The biotites of AGM are more ferric ( $\mathrm{Fe} \#$ between 0,5 to 0,8$)$ and aluminous (17 to $19 \%$ in $\mathrm{Al}_{2} \mathrm{O}_{3}$ ), between the annite and siderofilite pole; the biotites of GGM are more magnesian ( $\mathrm{Fe} \# \sim 0,5)$ and less aluminous ( 14 to $15 \%$ in $\mathrm{Al}_{2} \mathrm{O}_{3}$ ), and are situated between the poles of the phlogopite and eastonite ( $\mathrm{Fe}$ \# between $0,5$ to 0,8$)$. The biotites are preferentially primary and were a little modified by the deformation that affected the granites massifs. Compared to the others facies, the biotites of foliated facies have similar values in $\mathrm{MgO}$ and $\mathrm{TiO}_{2}$, being only more enriched in $\mathrm{Al}_{2} \mathrm{O}_{3}$.
\end{abstract}

Keywords: Shear zones, Arrozal Granite, Mineral Chemistry, Calc-alkaline

INTRODUÇÃO Os granitos do vale do Rio Paraíba do Sul, no Rio de Janeiro, foram classificados inicialmente em cinco tipos petrográficos: (1) biotita-granitos (Funil, Resende, Valão do Bambuí); (2) biotita- $( \pm$ anfibólio) granitos (São José do Barreiro, Varre-Sai); (3) biotita-( \pm granada) granitos (Rio Turvo); (4) biotita- $( \pm$ magnetita) (Valão da Laje) e, (5) anfibólio-biotita-granitóides (Suíte Serra das Abóboras) (Machado \& Peloggia 1987).

Posteriormente, estes granitos foram reunidos em três grupos tectônicos: um mais antigo, denominado de sin-F2 (Rio Turvo, Suíte Serra das Abóboras), um intermediário, designado de sin-F3 (Funil, Resende, São José do Barreiro, Varre-Sai, Valão do Bambuí e Valão da Laje) e outro mais novo, denominado sin-F4 (Pedra Branca, Nova Friburgo, Favela, Utinga, Macaé, Morro do Côco) (Machado \& Demange 1994, Heilbron et al. 1995). No grupo sin-F3, são ainda incluídos os granitos Arrozal, Vassouras, Getulândia, Anta, Parati e Parati-Mirim (Machado \& Demange 1994).

Os granitos sin-F2 são descritos como rochas foliadas, sendo comum o desenvolvimento de estruturas gnáissicas e miloníticas nas bordas, tendo a sua parte central isótropa. Os corpos são concordantes com

1 - Universidade Federal Rural do Rio de Janeiro, Seropédica, RJ. E-mail: nummer@ufrrj.br

2 - Departamento de Geologia da Escola de Minas de Ouro Preto, Ouro Preto, MG. E-mail: luseixas@ufop.br

3 - Instituto Geociências da USP e Pesquisador do CNPq, São Paulo, SP. E-mail: rmachado@usp.br 
a estruturação regional e foram alojados em nível crustal de Fácies Anfibolito, grau médio, sendo considerados como plutons catazonais (Machado \& Demange 1994).

Os granitos sin-F3 são descritos como maciços foliados, concordantes com a estruturação regional, sendo comuns a presença de estruturas magmáticas no seu interior e deformacionais nas bordas, onde são freqüentes tipos protomiloníticos e miloníticos, ao lado de gnaisses listrados com bandamento fino, centimétrico a milimétrico (Machado \& Demange 1984, Machado 1977). Estes granitos estão associados às zonas de cisalhamento de alto ângulo do vale do Rio Paraíba do Sul. Predominam rochas de granulação média a grossa, inequigranulares a porfiríticas, leucocráticas, de composição não expandida (monzogranítica a granodiorítica), podendo ocorrer ainda dioritos e quartzo dioritos (Machado \& Demange 1994). Duas idades U-Pb em monazita, obtidas no granito Getulândia, forneceram valores de 532 e $538 \mathrm{Ma}$ (Machado et al. 1996, Valladares 1996). Foram obtidas ainda idades U-Pb em monazita de $579 \pm 6 \mathrm{Ma}$, para o granitóide Rio Turvo (Machado et al. 1996), e idades $\mathrm{Pb} / \mathrm{Pb}$ (em zircão, por evaporação) no intervalo de 584 e $605 \mathrm{Ma}$, para os granitos Funil, São José do Barreiro, Mendanha e Capivara, os quais são relacionados à fase sincolisional do Cinturão Ribeira (Pereira et al. 2002).

Neste trabalho são apresentados os dados de química mineral (feldspato alcalino, plagioclásio e biotita) de 13 amostras, sendo 9 do Maciço Granítico Arrozal fácies porfirítica, foliada, leucogranítica, e enclave quartzo diorítico), e 3 do Maciço Granítico Getulândia (fácies inequigranular rosada, equigranular cinza foliada) e uma da rocha encaixante (Ortognaisses Quirino).

GRANITOGÊNESE BRASILIANA NO RIO DE JANEIRO Inúmeros trabalhos têm sido publicados sobre a granitogênese brasiliana no estado do Rio de Janeiro. Contudo, em geral são trabalhos relacionados aos granitos tardios (sin- a tardi-F3 e sin-F4), com características tardi- a pós-tectônicas, sobretudo localizado na Região Serrana do estado (Petrópolis / Teresópolis) e arredores da cidade do Rio de Janeiro (Leonardos Jr. 1973; Pires et al. 1982; Penha 1984; Penha et al. 1980; Penha \& Wiedemann 1984; Junho 1982, 1991, 1993 e 1998; Junho \& Penha 1985; Junho et al. 1987; Wiedemann et al. 1987; Caddah et al. 1987; Porto Jr. et al. 1992; Puget \& Penha 1980; Zorita \& Penha 1980; Hippertt 1990; Machado 1990 e Machado \& Demange 1992, havendo, no entanto, poucos trabalhos que objetivem a integração regional e com proposta de classificação dos diferentes tipos de granitos (Machado \& Peloggia 1987, Machado \& Demange 1992 e 1994, Machado 1997, Heilbron 1995, Heilbron et al. 1995, Junho 1998). Estes trabalhos contêm, principalmente, informações cartográficas, petrográficas, geoquímicas e, mais raramente, tectônicas e geocronológicas.

Os dados geocronológicos existentes sobre os granitos do Rio de Janeiro apontam idades brasilianas (Ledent \& Pasteels 1968, Cordani et al. 1968 e 1973,
Delhal et al. 1969, Cordani \& Teixeira 1979, Siga Jr et al. 1982, Fonseca et al. 1979, Machado Filho et al. 1983, Fonseca et al. 1984, Fonseca et al. 1979, Batista 1984, Batista \& Kawashita 1985, Dias Neto et al. 1995, Machado N. et al. 1996, Valladares 1996, Valladares et al. 1995, Machado et al. 1996, Machado 1997, Tupinambá 1999, Pereira et al. 2002, Silva et al. 2003).

As primeiras observações sistemáticas sobre os granitos do Rio de Janeiro foram efetuadas por Hembold et al. (1965) na cidade do Rio de Janeiro. Nesta ocasião, foi produzido o primeiro mapa geológico do Maciço Pedra Branca, na escala 1: 50.000. Os vários trabalhos realizados posteriormente neste maciço não conseguiram modificar significativamente a sua representação cartográfica original. Outros granitos, como Pedra de Guaratiba e Campo Grande foram relacionados ao Maciço Pedra Branca por Hembold (1967).

Posteriormente, Leonardos Jr. (1973) classifica estratigraficamente as rochas graníticas da Serra dos Órgãos em oito tipos (do mais antigo para o mais novo): (1) migmatitos graníticos; (2) gnaisse tonalítico; (3) adamelito com hornblenda; (4) granito grosso; (5) quartzo diorito fino foliado; (6) granodiorito fino; (7) granito cinza, de granulação média a fina e, (8) granitos aplíticos rosados. Destes, apenas os tipos 4 e 7 ocorreriam nos arredores da cidade do Rio de Janeiro. Os tipos 6 e 8 não são deformados, enquanto os tipos 4 e 5 são afetados por um evento de deformação (F2), e os tipos 2 e 3, por dois eventos de deformação (F1 e F2).

Dos granitos tardi- a pós-tectônicos do Rio de Janeiro, os melhores estudados são os maciços Pedra Branca, Nova Friburgo, Frades, Getulândia, Fortaleza e Arrozal, sobre os quais existe um grande volume de dados petrográficos e litogeoquímicos (Junho \& Wiedemann 1987, Junho et al. 1987 e 1991, Junho 1993, Valladares 1996, Nummer 2001). Os autores têm demonstrado semelhanças químicas e texturais entre as rochas dos três primeiros maciços e têm identificado cinco faciologias principais, comparáveis entre si, e com a seguinte ordem estratigráfica (da mais jovem para a mais antiga): (1) leucogranito aplítico e pegmatitos; (2) granitos porfiríticos; (3) granitos megaporfiríticos; (4) granodiorito e (5) enclaves microgranulares.

As propostas de classificação regional sobre os granitos aqui estudados, referidos na literatura como sin-F3, encontram-se, sobretudo nos trabalhos de Machado \& Peloggia (1987), Machado \& Demange (1994),Machado (1997) e Junho (1998). O primeiro trabalho contém uma síntese das informações geológicas disponíveis na época sobre esses granitos, juntamente com classificação com base mineralógica. Os dois últimos apresentam classificações estrutural e tectônica dessas rochas, levando em consideração os domínios estruturais de ocorrência, as fases de deformações regionais, o nível crustal de colocação, o tipo composicional e os dados geocronológicos disponíveis. Estas informações permitem caracterizá-los em três grupos tectônicos principais, do mais antigo para o mais novo, como sin-F2, sin-F3 e sin-F4 (Machado \& Demange 1992, 1994). O primeiro grupo tem idade ao redor de 
$620 \mathrm{Ma}$, o segundo, entre 570 e $530 \mathrm{Ma}$, e o terceiro, ao redor de $500 \mathrm{Ma}$ (Machado et al. 1996).

Os granitos sin-F2 são descritos como grandes batólitos lineares, foliados, afetados pela deformação regional, e exibem uma foliação mais intensa nas bordas, onde são freqüentes estruturas gnáissicas e miloníticas. Eles são divididos em dois grupos: um mais homogêneo, de composição expandida (tonalito/ granodiorito/granito), com idade ao redor de $620 \mathrm{Ma}$, comparável aos granitos tipo-I Cordilherano; e, outro mais heterogêneo, constituído por granitóides tipo-S, com idade ao redor de 600 Ma. A colocação destes granitos teria ocorrido sob condições metamórficas de Fácies Anfibolito a Granulito, na seguinte ordem de profundidade (do mais raso para o mais profundo): (1) Serra dos Órgãos, (2) Serra das Araras, Rio Turvo, (3) Niterói, (4) Bela Joana (Machado et al.1989, Machado \& Demange 1994).

Os granitos sin-F3 são corpos menores, muitas vezes foliados, alongados, colocados em nível crustal da Fácies Anfibolito a Xisto-Verde, dominando composições monzo a sienogranítica, sendo intimamente associados com zonas de cisalhamento dúcteis de alto ângulo, sobretudo na região do vale do Rio Paraíba do Sul. Estes granitos apresentam estruturas magmáticas na parte central e deformacional nas bordas, sendo aí englobados os granitos Vassouras, Getulândia, Fortaleza, Arrozal, Varre-Sai, Anta, Parati e Parati-Mirim, Funil, Resende, dentre outros (Machado \& Demange 1994, Machado 1997).

Os granitos sin-F4 são caracterizados como corpos menores, homogêneos, sub-arredondados, ocorrendo na forma de stocks (diâmetro médio de $10 \mathrm{Km}$ ), não deformados, de composição monzogranítica a álcali-feldspato granítica, de colocação mais rasa do que os anteriores. A sua colocação é considerada independente da estruturação regional NE-SW. Ocorrência mais expressiva são encontradas na região serrana do Rio de Janeiro e nos arredores da Baía de Guanabara. Foram aqui incluídos os granitos Mangaratiba, Mambucaba, Nova Friburgo, Suruí, Andorinha, São Pedro, Utinga, Sana, dentre outros (Machado e Demange 1994 e Machado 1997).

Heilbron (1995) e Heibron et al. (1995), ao discutirem a granitogênese brasiliana no Estado do Rio de Janeiro, dividem os granitóides com base nas fases de deformação regionais, de forma similar ao que fizeram Machado et al. (1989) e Machado \& Demange (1991, 1992, 1994), separando estas rochas em quatro grupos: (1) contemporâneos à deformação principal $-\mathrm{D}_{1}+\mathrm{D}_{2}$, acompanhada de metamorfismo $\mathrm{M}_{1}$; (2) tardios à deformação principal; (3) sin- a tardi-D 3 , acompanhada de metamorfismo $M_{2}$ e, (4) pós-tectônicos. Dentro destes grupos, Heibron (1995) separa cinco tipos de granitos, designando-os, dos mais antigos para os mais novos, de: $\gamma_{1}$ e $\gamma_{2}$ (grupo 1); $\gamma_{3}$ (grupo 2); $\gamma_{4}$ (grupo 3) e, $\gamma_{5}$ (grupo 4).

No primeiro tipo de granitóides (Heilbron 1995) são incluídos o Batólito Serra dos Órgãos e os gnaisses facoidais; no segundo, os maciços do Rio Turvo, Serra da Concórdia, granada charnockitóides de Juiz de Fora, granitóide Matias Barbosa e leucogranitos tipo-S intrusivos no Andrelândia; no terceiro, Serra do Lagarto e Taquaral; no quarto, os leucogranitos tipo-I diferenciados, Serra do Ipiranga ou Vassouras, Getulândia, Fortaleza, Araras e Pedra Branca; no quinto, os granitos tipo Favela, Nova Friburgo, Sana, Teresópolis e Caju.

Trabalhos regionais, realizados no Espírito Santo e norte do Rio de Janeiro, têm reconhecido a existência de magmatismo cálcio-alcalino e álcali-cálcico relacionado a um arco magmático brasiliano, que teria se desenvolvido no intervalo de 590-480 Ma, para o qual é proposta a denominação de "Arco Magmático Rio Doce" (Figueiredo \& Campos Neto 1993). Este mesmo arco foi também postulado para a região por Wiedemann (1993), porém com intervalo mais amplo, entre 580 e $450 \mathrm{Ma}$.

Machado (1997) propõe a divisão tectônica do magmatismo granítico Neoproterozóico do Rio de Janeiro em quatro estágios: (1) pré-colisional (620 a 650 Ma), (2) sincolisional (600 a 590/570 Ma), (3) tardi-colisional (560 a $530 \mathrm{Ma}$ ) e, (4) pós-colisional (520 a 480 Ma). O primeiro estágio é relacionado com a subducção da litosfera oceânica; o segundo, a um forte espessamento crustal associado ao metamorfismo regional de pressão média/baixa, com geração de granitos tipo-S (dominante) e tipo-I (subordinado), envolvendo sobretudo, fusão de rochas metassedimentares aluminosas; o terceiro, é relacionado à evolução intracontinental do cinturão, com o magmatismo sendo controlado essencialmente por zonas de cisalhamento transcorrentes destrais, de expressão litosférica; e, o quarto, é vinculado a um regime extensional resultante do colapso do edifício orogênico.

Machado \& Dehler (2002), em trabalho de revisão e reavaliação dos granitos tipo-S do Rio de Janeiro, consideram estes granitos como relacionados a um ambiente tectônico tardi-colisional, cuja geração do magmatismo se deu sob condições de uma crosta espessada. Os autores enfatizam a importância das zonas de cisalhamento (de alto e baixo ângulo) durante a colocação destes granitos.

MACIÇO GRANÍTICO ARROZAL - MGA Este maciço ocorre na porção sudoeste do estado Rio de Janeiro, nas imediações da cidade de Volta Redonda, já próximo da divisa com São Paulo (Fig. 1). Trata-se de um corpo granítico alongado, com eixo maior na direção ENEWSW, associado com o sistema de cisalhamento dúctil de alto ângulo do Vale do Rio Paraíba do Sul. Possui cerca de $40 \mathrm{~km}$ de extensão por $7 \mathrm{~km}$ de largura. Apresenta foliação magmática na parte central e deformação no estado sólido em direção às bordas. Os contatos com as rochas encaixantes são sempre tectônicos, balizados por zonas de cisalhamento de alto ângulo, onde é comum o desenvolvimento de rochas protomiloníticas e miloníticas.

Este maciço apresenta características de granitos tipo-I Caledoniano, com provável desenvolvimento em ambiente tardi-colisional, confirmando assim tra- 


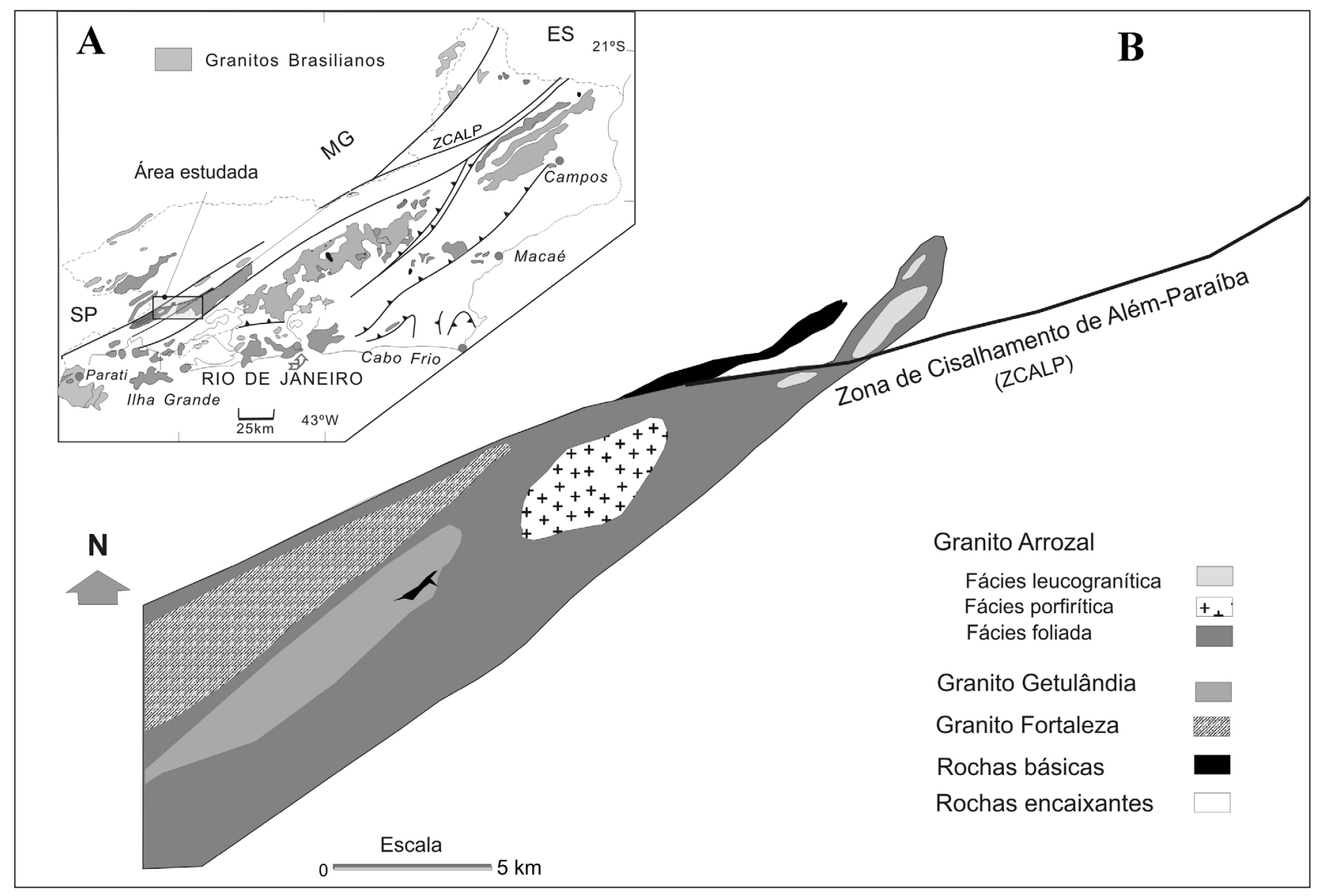

Figura 1 - Mapa de localização da área investigada (A) e mapa de divisão de Fácies do Maciço Granítico Arrozal (B).

balhos anteriores disponíveis na literatura (Machado \& Demange 1994, Machado 1997, Nummer 2001). A idade do Maciço Granítico Arrozal deve ser muito próxima da idade obtida em maciços similares como Getulândia, cujas datações radiométricas forneceram idades $\mathrm{U}-\mathrm{Pb}$ (em monazita) de 532 e $538 \mathrm{Ma}$ (Machado et al. 1996, Valladares 1996).

Petrografia O Maciço Granítico Arrozal, do ponto de vista cartográfico, foi separado em três faciologias principais (Nummer 2001): (i) Fácies Porfirítica, (ii) Fácies Foliada e, (iii) Fácies Leucogranítica (Fig 1B).

A Fácies Porfirítica ocorre principalmente na parte central do maciço e perfaz cerca de $20 \%$ da sua área mapeada. Caracteriza-se por granulação média a grossa, textura inequigranular a levemente porfirítica, com presença de megacristais $(0,5$ a $2,0 \mathrm{~cm})$ esparsos de feldspato potássico e plagioclásio, que perfazem entre 5 a $15 \%$ do volume da rocha. Os minerais essenciais são feldspato potássico (microclínio), plagioclásio, quartzo e biotita; os acessórios são granada, epídoto, zircão, apatita e minerais opacos, ocorrendo ainda carbonato, sericita e mica branca como minerais de alteração.

Os feldspatos são euédricos a subédricos, retangulares, desenvolvendo localizadamente texturas em synneusis. O plagioclásio apresenta geminação segundo a lei da Albita; o quartzo exibe forma equidimensio- nal e não apresenta evidências de deformação.

A Fácies Foliada representa mais de $2 / 3$ da área do maciço, sendo encontrada principalmente nas bordas do mesmo. Nesta faciologia é comum a presença de uma pronunciada estrutura bandada, caracterizada pela alternância de leitos melanocráticos ricos em biotita, de espessura centimétrica, contendo muitas vezes hornblenda, com leitos leucocráticos ricos em quartzo e feldspato. Curiosamente, algumas das amostras desses locais não exibem evidências de deformação em lâmina delgada, sugerindo, portanto, que pelo menos parte do bandamento observado em campo foi originado por processos de natureza ígnea.

Esta fácies caracteriza-se por uma granulação média a grossa, estrutura muitas vezes milonítica, onde se destacam porfiroclastos lenticulares de feldspato alcalino associados com fitas de quartzo e lamelas de biotita, dispostos em uma matriz mais fina, constituída por agregado quartzo-feldspático. Os porfiroclastos de feldspato alcalino são, em geral, pertíticos e os de plagioclásio, antipertíticos, sendo ambos deformados, com forma usualmente lenticular e elipsoidal. Ocorre ainda associada outra fácies de granulação mais grossa ( $\mathrm{mi}$ lonito gnaisse, sensu Higgins 1971), a qual se mostra mais enriquecida em quartzo e empobrecida em biotita do que a fácies anterior. Os minerais essenciais são plagioclásio, microclínio, quartzo e biotita; os acessó- 
rios são epídoto, zircão, clorita, mica branca, apatita e minerais opacos, podendo ocorrer ainda granada e turmalina.

A Fácies Leucogranítica ocorre na parte centronorte do maciço, a leste da localidade de Arrozal. Tratase de um pequeno corpo alongado $(2,8 \times 0,4 \mathrm{~km})$, que ocupa menos de $10 \%$ da área de exposição do maciço (Fig. 1B). São rochas de granulação média a grossa, inequigranulares e porfiríticas, leucocráticas, rosadas e esbranquiçadas, contendo muitas vezes enclaves microgranulares decimétricos, com composição diorítica a quartzo diorítica. Os minerais essenciais são plagioclásio, quartzo e ortoclásio, ocorrendo como acessórios a biotita, granada, minerais opacos, hornblenda, titanita, zircão e epídoto.

Química mineral As análises químicas de minerais foram realizadas no Laboratório de Microssonda Eletrônica da Universidade Federal do Rio Grande do Sul, utilizando-se um equipamento de microssonda eletrônica marca CAMECA SX-50, sob as seguintes condições operacionais: voltagem de aceleração de $15 \mathrm{kV}$; feixe de corrente elétrica de $10 \mathrm{nA}$; tempo de contagem da análise de 30s, para F, Mg, Al, Na, Si e Sr, e de 20 s para $\mathrm{Cl}, \mathrm{K}, \mathrm{Ca}, \mathrm{Mn}$, Ti e Fe; diâmetro do feixe de elétrons de $1 \mu \mathrm{m}$ para biotita, $5 \mu \mathrm{m}$ para anfibólio e feldspato alcalino, e $10 \mu \mathrm{m}$ para plagioclásio.

A fórmula estrutural das biotitas foi calculada numa base anidra de 22 átomos de oxigênio (Deer et al. 1976). Assumiu-se que todo ferro presente encontra-se na forma de $\mathrm{Fe}^{2+}$ (Dymek 1983). Para a classificação dos anfibólios, utilizou-se a proposta de Leake et al. (1997). A fórmula estrutural dos feldspatos foi calculada em base anidra de 32 átomos de oxigênios (Deer et al. 1973).

Foram selecionadas 13 amostras para análise química dos minerais, sendo 9 amostras do Maciço Granítico Arrozal (3 da Fácies Porfirítica, 3 da Fácies Foliada, 2 da Fácies Leucogranítica e 1 de enclave básico), 3 do Maciço Getulândia (1 da Fácies Inequigranular Rosada, 1 da Fácies Equigranular cinza foliada e 1 de enclave básico) e 1 da rocha encaixante (ortognaisse da unidade Quirino). Foram analisados cristais de biotita, anfibólio, plagioclásio e feldspato alcalino. Foram realizados 185 análises: 75 em biotita, 13 em anfibólio, 27 em feldspato alcalino e 70 em plagioclásio. Sempre que possível as análises foram efetuadas no centro e borda dos cristais.

FELDSPATO A fórmula estrutural dos feldspatos foi calculada com base em 32 oxigênios (Deer et al. 1982) podendo ser escrita genericamente como:

$$
\left(\mathrm{A}_{\mathrm{x}}^{+1} \mathrm{~A}_{\mathrm{x}}^{+2}\right)\left(\mathrm{B}_{2-\mathrm{x}}^{+3} \mathrm{~B}_{2-\mathrm{x}}^{+4}\right) \mathrm{O}_{8} \text {, para } 0<\mathrm{x}<1
$$

Estes feldspatos são representados pelo feldspato alcalino (ortoclásio e microclina) e plagioclásios, que são descritos abaixo.

Feldspato Alcalino Ao microscópio, o feldspato al- calino das Fácies Porfirítica e Foliada do MGA ocorre como megacristal subedral e como integrante da matriz. Nesta, possui forma subedral a anedral, aparecendo também como inclusões subarredondadas no plagioclásio. Os megacristais apresentam-se límpidos (até $5 \mathrm{~cm}$ ) e caracterizam-se opticamente como ortoclásio. $\mathrm{Na}$ matriz caracteirzam-se como microclínio. Na Fácies Leucogranítica, equigranular, ele é micropertítico e ocorre como cristal subedral, com dimensões entre 0,5 a $1,5 \mathrm{~mm}$. Na Fácies Porfirítica, a sua composição no diagrama triangular $\mathrm{Or}-\mathrm{Ab}$ - An situa-se próximo ao pólo do Ortoclásio, com valores de moléculas de Albita sempre inferiores a 20\% (Fig. 2). Na Fácies Foliada, a sua composição é sempre inferior ao valor em Or da Fácies Leucogranítica. Foram observadas pequenas variações composicionais centro-borda nos feldspatos
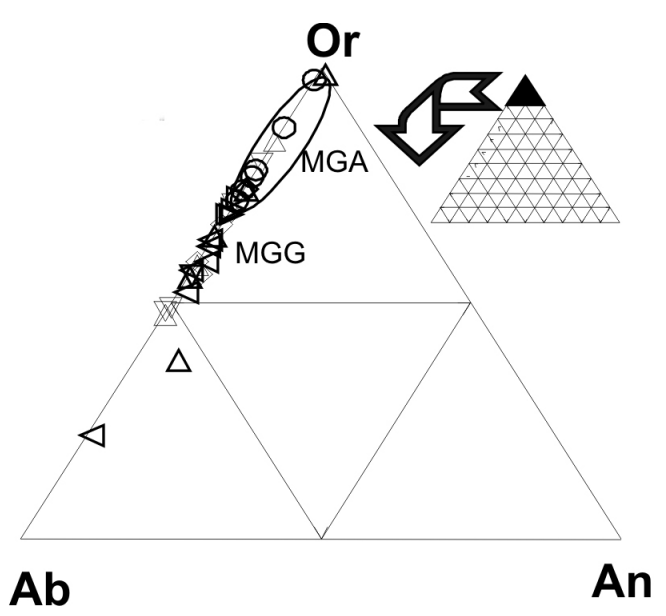

Figura 2 - Composição dos feldspatos da fácies porfiritica (círculo vazio) e da fácies leucogranitica (triângulo normal vazio) do Maciço Granítico Arrozal (MGA) e da fácies inequigranular (triângulo invertido vazio) do Maciço Granítico Getulândia $(M G G)$ no diagrama triangular Or-Ab-A.

alcalinos, com os teores em Ca sendo mais elevados no núcleo.

Plagioclásio Em lâmina delgada, o plagioclásio das três fácies do MGA ocorre principalmente como integrante da matriz. São cristais com geminação polissintética da Albita, não zonados, com tamanho variáveis entre $1 \mathrm{a} 4 \mathrm{~mm}$, exibindo graus variáveis de saussuritização. Nas porções mais deformadas da Fácies Foliada, apresentam geminações polissintéticas em cunha. Ocorrem também como grãos límpidos, euedrais a subedrais, às vezes arredondados, como integrantes da matriz ou intersticiais.

Os dados de química mineral permitiram separar três grupos composicionais de plagioclásio (Tab. 1): o primeiro grupo, que apresenta composição albítica, é encontrado nas Fácies Leucogranítica (MGA) e no gnaisse encaixante; o segundo grupo, de composi- 
Tabela 1 - Análises de microssonda selecionadas de plagioclásios do Maciço Granítico Arrozal (MGA),

\begin{tabular}{|c|c|c|c|c|c|c|c|c|c|c|c|c|c|}
\hline \multirow{3}{*}{$\begin{array}{l}\text { Maciço } \\
\text { Fácies } \\
\text { Análise }\end{array}$} & \multicolumn{13}{|c|}{ Arrozal } \\
\hline & \multicolumn{3}{|c|}{ Leucogranítica } & \multicolumn{3}{|c|}{ Porfirítica } & \multicolumn{4}{|c|}{ Foliada } & \multicolumn{3}{|c|}{ Enclave } \\
\hline & DP228 & DP236 & DP231 & EP90 & EP96 & FP170 & IP152 & LP26 & NP223 & LP19 & JP141 & JP145 & JP150 \\
\hline $\mathrm{SiO} 2$ & 64,28 & 64,56 & 69,93 & 60,64 & 59,67 & 61,79 & 61,21 & 64,47 & 60,58 & 65 & 45,43 & 62,86 & 44,84 \\
\hline $\mathrm{A} 12 \mathrm{O} 3$ & 23,43 & 23,49 & 19,97 & 25,82 & 26,60 & 25,07 & 25,43 & 23,38 & 26,13 & 24 & 35,78 & 24,87 & 36,07 \\
\hline $\mathrm{FeO}$ & 0,13 & 0,03 & 0,00 & 0,02 & 0,00 & 0,00 & 0,00 & 0,01 & 0,09 & 0 & 0,00 & 0,11 & 0,06 \\
\hline $\mathrm{MgO}$ & 0,008 & 0,00 & 0,00 & 0,00 & 0,00 & 0,003 & 0,00 & 0,01 & 0,00 & 0 & 0,00 & 0,00 & 0,00 \\
\hline $\mathrm{CaO}$ & 4,42 & 4,57 & 0,30 & 7,22 & 7,77 & 6,31 & 6,63 & 4,16 & 7,64 & 4 & 18,62 & 5,83 & 19,17 \\
\hline $\mathrm{Na} 2 \mathrm{O}$ & 7,97 & 7,50 & 9,94 & 6,42 & 6,09 & 6,98 & 7,09 & 8,31 & 6,21 & 8 & 0,82 & 7,23 & 0,60 \\
\hline $\mathrm{K} 2 \mathrm{O}$ & 0,24 & 0,31 & 0,08 & 0,23 & 0,32 & 0,20 & 0,19 & 0,25 & 0,14 & 0 & 0,004 & 0,03 & 0,008 \\
\hline $\mathrm{BaO}$ & 0,02 & 0,19 & 0,09 & 0,00 & 0,00 & 0,07 & 0,00 & 0,00 & 0,00 & 0 & 0,13 & 0,00 & 0,17 \\
\hline \multirow[t]{2}{*}{ Total } & 100,52 & 100,68 & 100,34 & 100,36 & 100,46 & 100,45 & 100,58 & 100,61 & 100,81 & 12 & 100,80 & 100,95 & 100,94 \\
\hline & & centro & borda & $\operatorname{Mega}(M)$ & Mega & & & & & & & & \\
\hline
\end{tabular}

Tabela 1 (cont.) - Análises de microssonda selecionadas de plagioclásios do Maciço Granitico Getulândia (MGG) e dos ortognaisses encaixantes da Unidade Quirino,

\begin{tabular}{l|c|c|c|c|c|c|c|c|c}
\hline Maciço & \multicolumn{5}{|c|}{ Getulândia } & \multicolumn{4}{c}{ Quirino } \\
\hline Fácies & \multicolumn{2}{|c|}{ Inequigranular Rosada } & \multicolumn{2}{|c}{ Enclave diorítico } & \multicolumn{3}{c}{ Ortognaisse } \\
\hline Análise & CP79 & CP80 & CP82 & BP207 & MP29 & MP34 & GP85 & GP86 & GP87 \\
\hline MgO & 0,00 & 0,007 & 0,006 & 0,01 & 0,00 & 0,00 & 0,00 & 0,00 & 0,00 \\
\hline Al2O3 & 25,07 & 25,23 & 25,28 & 20,17 & 28,49 & 25,41 & 22,63 & 22,75 & 22,86 \\
\hline K2O & 0,34 & 0,26 & 0,39 & 0,12 & 0,21 & 0,40 & 0,17 & 0,20 & 0,29 \\
\hline CaO & 6,31 & 6,56 & 6,89 & 0,78 & 10,09 & 6,75 & 3,66 & 3,80 & 3,67 \\
\hline FeO & 0,11 & 0,16 & 0,15 & 0,08 & 0,03 & 0,05 & 0,11 & 0,03 & 0,12 \\
\hline BaO & 0,00 & 0,05 & 0,07 & 0,15 & 0,00 & 0,06 & 0,00 & 0,15 & 0,23 \\
\hline Na2O & 6,49 & 6,79 & 6,38 & 9,47 & 4,88 & 6,69 & 8,02 & 7,83 & 8,36 \\
\hline SiO2 & 61,43 & 61,40 & 61,03 & 68,41 & 56,22 & 60,89 & 65,10 & 65,04 & 65,42 \\
\hline Total & 99,77 & 100,49 & 100,22 & 99,21 & 99,94 & 100,27 & 99,71 & 99,83 & 100,98 \\
\hline
\end{tabular}

ção andesina, está presente na Fácies Equigranular do MGG, na Fácies Porfirítica e Foliada do MGA, e no enclave quartzo diorítico do último maciço; o terceiro grupo é composto por plagioclásio de composição anortítica, oriundo de amostras do enclave diorítico (composição labradorita e bytownita) do MGG.

O plagioclásio do enclave, de composição anortítica, possui valores anômalos em sódio (entre 6,9 a $7,2 \%$, Tab. 1). O plagioclásio presente na micropertita tem composição mais cálcica.

De modo geral, os megacristais têm composições menos sódicas do que os cristais da matriz, para uma mesma faciologia, bem como as bordas dos cristais da matriz são mais sódicas do que seus núcleos BIOTITA Foram analisadas 9 amostras, incluindo 6 do MGA (em granitos e enclave), 1 do MGG (enclave diorítico) e 1 do ortognaisse encaixante (Tab. 2).

A fórmula estrutural da biotita foi calculada numa base anidra de 22 átomos de oxigênio (Deer et al. 1982), com a fórmula geral sendo expressa da seguinte maneira:

$$
\mathrm{K}_{2}\left(\mathrm{Mg}, \mathrm{Fe}^{2+}\right)_{6-4}\left(\mathrm{Fe}^{3+}, \mathrm{Al}, \mathrm{Ti}\right)_{0-2}\left[\mathrm{Si}_{6-5} \mathrm{Al}_{2-3} \mathrm{O}_{20}\right](\mathrm{OH}, \mathrm{F})
$$

A biotita é o principal mineral máfico presente nas diferentes faciologias estudadas, com volume entre 0,5\% (Fácies Leucogranítica do MGA) a 20\% (Fácies Foliada do MGA).

Microscopicamente, os cristais de biotita estudados possuem características ópticas distintas nos dois maciços: no MGA apresentam pleocroísmo de marromavermelhado a pardo-esverdeado, enquanto no MGG, 
de verde-claro a verde-escuro. Em ambos os maciços, elas possuem tamanho entre 1 e $3 \mathrm{~mm}$.

Ocorrem na forma de agregados na matriz ou como cristais intersticiais ao redor de megacristais de feldspatos potássico e plagioclásio. Nos enclaves, ela ocorre tanto na forma de cristais intersticiais, esparsos, de tamanho submilimétrico, parcial ou totalmente cloritizados, como em agregados intersticiais associados com minerais opacos, hornblenda, clorita e mica branca secundária. Em algumas amostras, observa-se a alteração para mica branca e clorita.

Classificação As análises de biotita indicam composição annítica para a Fácies Leucogranítica e rocha encaixante, enquanto as Fácies Porfirítica e Foliada mostram-se menos enriquecidas em $\mathrm{FeO}$ do que na Fácies Leucogranítica. A biotita da Fácies Equigranular do MGG é a mais magnesiana de todas ( $\mathrm{Fe} \# \sim 0,5)$. O trend de evolução destas biotitas (Fig. 3A) indica um caráter mais evoluído para a Fácies Leucogranítica.

No diagrama triangular $10 * \mathrm{TiO} 2$ vs. $\mathrm{FeO}+$ $\mathrm{MnO}$ vs. $\mathrm{MgO}$ de Nachit et al. (1986), proposto para discriminar biotita primária e secundária, as biotitas estudadas ocupam o campo de biotita primária (Fig. 3B). Porém, de acordo com a proposta de Abdel-Rahman
(1994) (Fig. 3E), os teores de $\mathrm{Al}_{2} \mathrm{O}_{3}$ da biotita das Fácies Porfirítica e Foliada (entre 16-18\%) se encontram no limite entre os grupos de biotita primária (magmáticas) e secundária (alteração), sendo este campo representado por biotita que sofreu modificações composicionais por processos de substituições associados a fluídos da fase tardi- a pós-magmática.

Na Fácies Foliada, a composição da biotita analisada permite distinguir dois grupos: um grupo magmático e outro alterado. O primeiro grupo, muito férrico (annita), com cristais límpidos e alongados, caracteriza-se por teores de $\mathrm{Al}_{2} \mathrm{O}_{3}$ entre 13,90 e $14,29 \%$, $\mathrm{MgO}$ entre 9,70 e $10 \%$ e $\mathrm{TiO}_{2}$ entre 4,8 e 5,8\% (Tab. 2). Este grupo é considerado magmático e, portanto, o seu quimismo deve refletir a composição química do líquido que the deu origem. O segundo grupo, mais comum do que o anterior, caracterizado por composição siderofilita, apresenta teores em $\mathrm{Al}_{2} \mathrm{O}_{3}$ entre 17,56 e $18,95 \%, \mathrm{MgO}$ entre 6,6 e $8,1 \%$ e $\mathrm{TiO}_{2}$ entre 2,6 e $3,8 \%$. Este grupo é texturalmente diferente das biotitas do primeiro grupo, apresentando-se com as lamelas de contornos corroídos, orientadas segundo a foliação milonítica. Pelo exposto, sugere-se que as diferenças composicionais apresentadas pelas biotitas do segundo grupo estejam relacionadas a processos de deformação
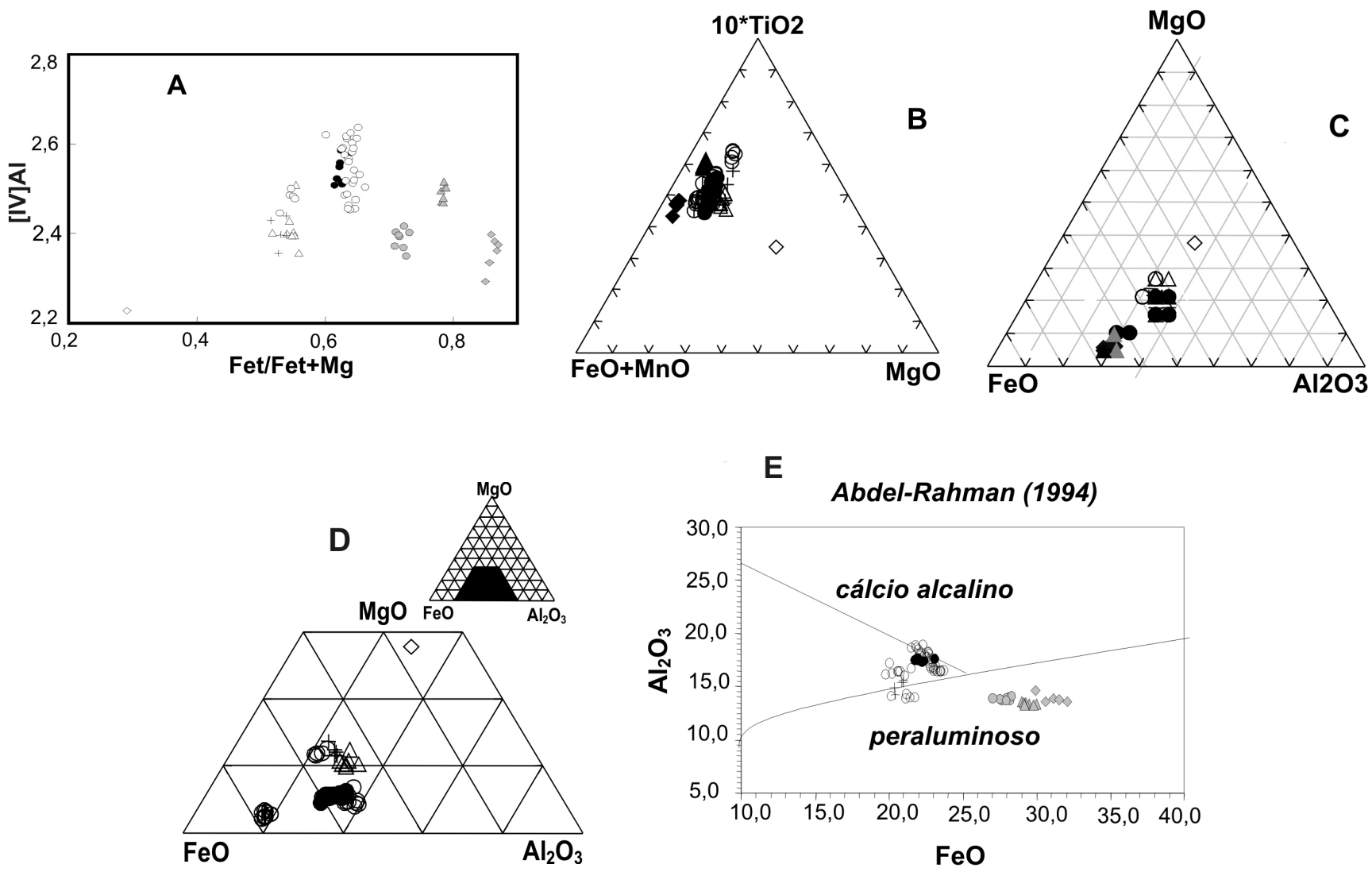

Figura 3 - Composição das biotitas dos Maciços Graniticos Arrozal (MGA) e Getulândia (MGG) nos diagramas $\mathrm{Fe}^{t} / \mathrm{Fe}^{t}+\mathrm{Mg}$ vs. $\mathrm{Al}^{\mathrm{IV}}(\mathrm{A}), \mathrm{FeO}+\mathrm{MnO}-10^{*} \mathrm{TiO}_{2}-\mathrm{MgO}$ (B) de Nachit et al. (1986), $\mathrm{FeO}-\mathrm{MgO}-\mathrm{Al}_{2} \mathrm{O}_{3}(\mathrm{C}$ e D) e $\mathrm{Al}_{2} \mathrm{O}_{3}$ vs. $\mathrm{FeO}(\mathrm{E})$ de Abdel-Rahman (1994), onde se acham representadas as Fácies Leucogranítica (círculo pontilhado), Porfiritica (círculo cheio), Foliada (círculo vazio) e enclave máfico (losângulo vazio) do MGA; Fácies Equigranular (cruz), Foliada (triângulo vazio) e enclave máfico (losângulo pontilhado) do MGG, e ortognaisse encaixante (triângulo pontilhado). 
associados a fluídos que afetaram o MGA (Tab. 2).

Um outro grupo de biotita analisada, pertencente às rochas encaixantes (ortognaisses da Unidade Quirino) dos maciços graníticos, caracteriza-se pelos elevados teores em $\mathrm{FeO}, \mathrm{TiO}_{2}$, e mais baixos em $\mathrm{SiO}_{2}$ e $\mathrm{MgO}$.

Os grupos de biotitas, em geral, apresentam razão $\mathrm{Fe} \#(\mathrm{Fe} /(\mathrm{Fe}+\mathrm{Mg})$ entre 0,3 a 0,9 , com valores de $\mathrm{Al}^{\mathrm{IV}}$ situados no intervalo de 2,3 a 2,6 (Tab. 2). No diagrama $\mathrm{Al}^{\mathrm{IV}}$ vs. Fe \# (Fig. 3A), as biotitas do MGA situam-se no campo das micas aluminosas a ligeiramente férricas ( $\mathrm{Al}^{\mathrm{IV}}$ entre 2,4 a 2,6 e Fe \# 0,6, situando-se entre os campos da annita e siderofilita), enquanto aquelas do MGG e algumas biotitas da Fácies Foliada mostram-se mais magnesianas $\left(\mathrm{Al}^{\mathrm{IV}}\right.$ entre 2,3 e 2,5 e Fe \# entre 0,5 e 0,6 ), situando-se entre os campos da flogopita e eastonita (Fig. 3A). A biotita dos enclaves máficos dos MGA e MGG dispõem-se no campo da annita (Fig. 3A).

Variações composicionais Os dados obtidos para as amostras do MGA e MGG revelam uma forte correlação inversa linear entre os conteúdos de $\mathrm{Al}^{\text {total }}$ vs. $\mathrm{Mg}$ (Fig. 4A). As biotitas do MGA (amostras FP, LP, EP e IP) possuem teores de $\mathrm{Al}^{\text {total }}$ superiores a $3 \%, \mathrm{Mg}<2 \%$, enquanto as biotitas do MGG (amostras CP, NP e BP) apresentam valores em $\mathrm{Al}^{\text {total }}$ inferiores a $3 \% \mathrm{e}, \mathrm{em} \mathrm{Mg}$, superiores a $2 \%$ (Fig. 4A; Tab. 2).

O conteúdo de $\mathrm{Mg}$ é mais elevado nas biotitas do enclave máfico (amostra JP: 2,8\% em $\underline{\mathrm{Al}^{\text {total }}}$ e 3,7\% em $\mathrm{Mg})$ e mais empobrecido nas biotitas $(\sim 1 \%)$ do gnaisse encaixante, com valores comparáveis nas Fácies Porfirítica, Foliada e no enclave máfico do MGA(entre 1,6 e $2,2 \%$ ), porém com valores relativamente baixos na Fácies Leucogranítica (entre 1,3 e 1,5\%) do mesmo (Fig. 3A; Tab. 2).

Há uma tendência de diminuição no conteúdo de $\mathrm{Cr}+\mathrm{Al}+\mathrm{Ti}\left(\mathrm{R}_{2}\right)$ com um aumento de $\mathrm{Mg}+\mathrm{Fe}^{+2} \mathrm{e}$ $\mathrm{Mn}\left(\mathrm{R}_{3}\right)$ na direção das biotitas do MGG (Fig. 4B). As razões $\mathrm{Al}^{\mathrm{IV}} v s$. FeOt / $(\mathrm{FeOt}+\mathrm{MgO})$ nas biotitas do MGA varia de 0,6 a $0,7 \%$, sendo estes valores ligeiramente mais elevados do que os apresentados pelo MGG (entre $0,5$ a $0,6 \%)$. As biotitas da rocha encaixante destacamse pelo valor anômalo de Fe \# ( 0,8\%) (Fig. 3A).

Diagramas discriminantes De acordo com a proposta de Abdel-Rahman (1994), os cristais de biotita das Fácies Porfirítica e Foliada do MGA ocupam preferencialmente o campo Cálcio-Alcalino, enquanto as demais (Fácies Leucogranítica, enclave diorítico, rocha encaixante e parte das amostras do MGG) ocupam campo Peraluminoso (Fig. 3E).

No diagrama de Chevremont et. al. (1988), observa-se que as amostras de biotita do MGA situam-se, parte no campo da Série Aluminosa, e parte no campo da Série Cálcio-Alcalina, com algumas amostras alocando-se no campo Subalcalino. As amostras do enclave diorítico do MGG, do gnaisse encaixante e da Fácies Leucogranítica do MGA situam-se no limite dos campos Subalcalino e Alcalino, evidenciando teores mais elevados em FeOt. As amostras do MGG ocupam, em
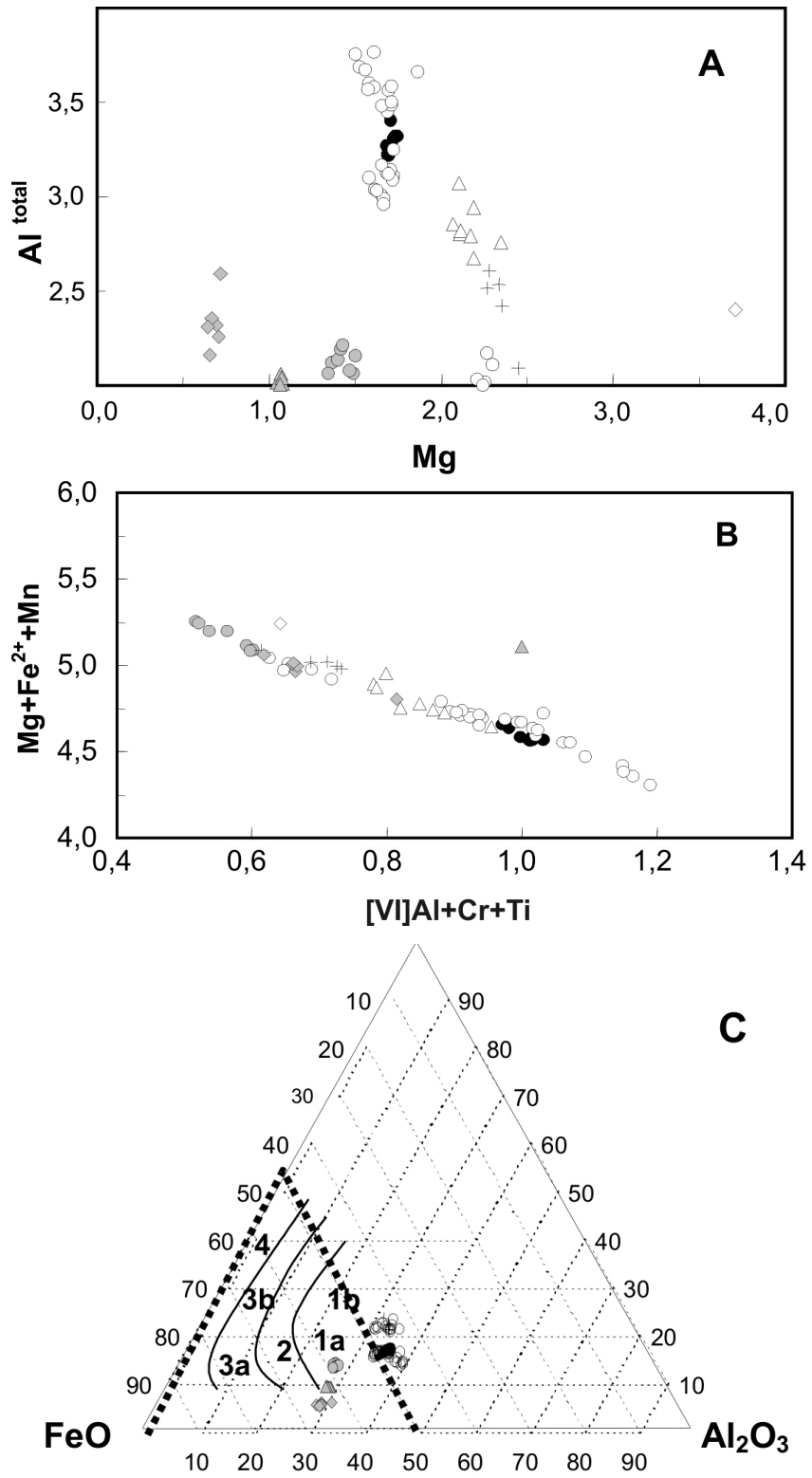

Figura 4 - Diagramas de substituição par a biotita dos Maciços Graníticos Arrozal (MGA) e Getulândia $(M G G)$ nos diagramas $M g$ vs. Altotal $(A), F^{t} / F e^{t}+M g$ vs. $\mathrm{Al}{ }^{\mathrm{IV}}(\mathrm{A}), \mathrm{FeO}+\mathrm{MnO}-10 * \mathrm{TiO}-\mathrm{MgO}$ (B) e $\mathrm{FeO}-$ $\mathrm{MgO}-\mathrm{Al}_{2} \mathrm{O}_{3}(\mathrm{C})$ de Chevremont et al. (1988), onde se encontram representadas as séries alumino-potássica tipo Limousin (1a), alumino-potássica tipo Gueret (1B), cálcio-alcalina (2) subalcalina ferro potássica(3a) e sub alcalina magnésio potássica (3B). Legenda como na Figura 3.

sua maioria, o campo Cálcio-Alcalino (Fig. 4C).

Substituições Foram testadas as substituições para o sítio octaédrico $\mathrm{R}^{+2} v s . \mathrm{R}^{+3} \mathrm{e} \mathrm{Al}^{\text {total }} v s$. Mg entre elementos e grupos de elementos químicos componentes das biotitas nas diferentes faciologias.

$\mathrm{O}$ gráfico $\mathrm{R}^{2+} v s . \mathrm{R}^{3+}$ apresenta uma excelente correlação linear negativa, indicando a existência de substituições entre os elementos $\mathrm{R}^{2+}\left(\mathrm{Fe}^{2+}+\mathrm{Mn}+\mathrm{Mg}\right)$ e 
Química mineral, cristalização e deformação de granitos sintectônicos brasilianos da região de Arrozal, SW do Rio de Janeiro

Tabela 2 - Análises de microssonda selecionadas de biotitas do Maciço Granítico Arrozal (MGA), (Ver continuidade na página 211)

\begin{tabular}{|c|c|c|c|c|c|c|c|c|c|c|}
\hline \multirow{3}{*}{$\begin{array}{l}\text { Maciço } \\
\text { Fácies } \\
\text { Amostra }\end{array}$} & \multicolumn{10}{|c|}{ Arrozal } \\
\hline & \multicolumn{2}{|c|}{ Leucogranítica } & \multicolumn{3}{|c|}{ Porfirítica } & \multicolumn{4}{|c|}{ Foliada } & \multirow{2}{*}{$\begin{array}{r}\text { Enclave } \\
\text { JP115 }\end{array}$} \\
\hline & DP178 & DP185 & EP57 & EP58 & FP116 & IP127 & IP137 & IP138 & LP14 & \\
\hline $\mathrm{SiO} 2$ & 35,7 & 35,60 & 35,68 & 35,70 & 35,35 & 34,89 & 35,54 & 35,57 & 35,86 & 40,36 \\
\hline TiO2 & 2,86 & 3,96 & 3,23 & 3,74 & 2,45 & 2,64 & 3,35 & 3,80 & 5,56 & 1,52 \\
\hline $\mathrm{Al2O3}$ & 13,94 & 13,65 & 17,47 & 17,39 & 16,53 & 17,56 & 16,45 & 16,41 & 13,83 & 16,02 \\
\hline $\mathrm{Cr} 2 \mathrm{O3}$ & 0,03 & 0 & 0,01 & 0,03 & 0 & 0,07 & 0,04 & 0,01 & 0,04 & 0,04 \\
\hline $\mathrm{FeO}$ & 28,13 & 27,97 & 21,95 & 22,21 & 23,19 & 22,81 & 23,04 & 23,56 & 21,16 & 12,71 \\
\hline MnO & 0,45 & 0,41 & 0,20 & 0,12 & 0,18 & 0,15 & 0,19 & 0,18 & 0,09 & 0,10 \\
\hline MgO & 6,42 & 5,75 & 7,58 & 7,54 & 7,39 & 7,29 & 7,03 & 7,26 & 9,83 & 17,40 \\
\hline $\mathrm{CaO}$ & 0 & 0,02 & 0,08 & 0,0 & 0,05 & 0,07 & 0,00 & 0,02 & 0,00 & 0,006 \\
\hline $\mathrm{Na2O}$ & 0 & 0 & 0,02 & 0 & 0,02 & 0,04 & 0,00 & 0,05 & 0,02 & 0 \\
\hline K2O & 10,04 & 9,81 & 9,76 & 9,87 & 9,66 & 9,69 & 9,94 & 9,57 & 10,12 & 9,03 \\
\hline $\mathbf{F}$ & 0,30 & 0,17 & 0,36 & 0,45 & 0,50 & 0,45 & 1,77 & 0,13 & 0,14 & 0,14 \\
\hline $\mathrm{Cl}$ & 0,19 & 0,18 & 0,15 & 0,14 & 0,21 & 0,15 & 0,21 & 0,23 & 0,02 & 0,04 \\
\hline \multirow[t]{2}{*}{ Total } & 98,11 & 97,57 & 96,54 & 97,27 & 95,56 & 95,84 & 97,60 & 96,85 & 96,71 & 97,41 \\
\hline & \multicolumn{10}{|c|}{ Fórmula estrutural na base de 23 átomos de oxigênios } \\
\hline $\mathbf{S i}$ & 5,59 & 5,59 & 5,47 & 5,45 & 5,53 & 5,43 & 5,52 & 5,48 & 5,49 & 5,77 \\
\hline AlIV & 2,40 & 2,40 & 2,52 & 2,54 & 2,46 & 2,56 & 2,47 & 2,51 & 2,49 & 2,22 \\
\hline Soma Z & 8,00 & 8,00 & 8,00 & 8,00 & 8,00 & 8,00 & 8,00 & 8,00 & 7,99 & 8,00 \\
\hline AIVI & 0,17 & 0,12 & 0,63 & 0,58 & 0,59 & 0,65 & 0,53 & 0,46 & 0,00 & 0,47 \\
\hline $\mathbf{T i}$ & 0,33 & 0,46 & 0,37 & 0,43 & 0,29 & 0,30 & 0,39 & 0,44 & 0,64 & 0,16 \\
\hline $\mathrm{Cr}$ & 0,004 & 0,00 & 0,001 & 0,004 & 0,00 & 0,009 & 0,005 & 0,002 & 0,006 & 0,005 \\
\hline $\mathrm{Fe} 2 \mathrm{t}$ & 3,68 & 3,67 & 2,81 & 2,83 & 3,03 & 2,97 & 2,99 & 3,03 & 2,71 & 1,52 \\
\hline Mn & 0,06 & 0,05 & 0,02 & 0,01 & 0,02 & 0,02 & 0,02 & 0,02 & 0,01 & 0,01 \\
\hline Mg & 1,50 & 1,34 & 1,73 & 1,71 & 1,72 & 1,69 & 1,62 & 1,66 & 2,24 & 3,71 \\
\hline Soma Y & 5,76 & 5,67 & 5,59 & 5,58 & 5,66 & 5,66 & 5,58 & 5,63 & 5,61 & 5,88 \\
\hline $\mathrm{Ca}$ & 0,00 & 0,00 & 0,01 & 0,005 & 0,00 & 0,01 & 0,00 & 0,00 & 0,00 & 0,001 \\
\hline $\mathrm{Na}$ & 0,00 & 0,00 & 0,008 & 0,000 & 0,00 & 0,01 & 0,00 & 0,01 & 0,007 & 0,00 \\
\hline K & 2,01 & 1,96 & 1,91 & 1,92 & 1,93 & 1,92 & 1,97 & 1,88 & 1,97 & 1,64 \\
\hline Soma X & 2,01 & 1,97 & 1,93 & 1,92 & 1,94 & 1,95 & 1,97 & 1,90 & 1,98 & 1,65 \\
\hline Total & 15,77 & 15,65 & 15,52 & 15,51 & 15,61 & 15,60 & 15,55 & 15,53 & 15,60 & 15,53 \\
\hline $\mathbf{F}$ & 0,15 & 0,08 & 0,17 & 0,22 & 0,24 & 0,22 & 0,87 & 0,06 & 0,06 & 0,06 \\
\hline Cl & 0,05 & 0,05 & 0,04 & 0,03 & 0,05 & 0,04 & 0,05 & 0,06 & 0,008 & 0,01 \\
\hline $\begin{array}{l}\mathrm{Mg} / \\
\mathrm{Mg}+\mathrm{Fe}\end{array}$ & 0,29 & 0,27 & 0,38 & 0,38 & 0,36 & 0,36 & 0,35 & 0,35 & 0,45 & 0,71 \\
\hline Alt & 2,57 & 2,53 & 3,16 & 3,13 & 3,05 & 3,22 & 3,01 & 2,98 & 2,49 & 2,70 \\
\hline
\end{tabular}


Tabela 2 (Cont) - Análises de microssonda selecionadas de biotitas do Maciço Granítico Getulândia (MGG) e dos ortognaisses encaixantes da Unidade Quirino,

\begin{tabular}{l|c|c|c|c|c|c}
\hline Maciço & \multicolumn{4}{|c|}{ Getulândia } & \multicolumn{2}{c}{ Unidade Quirino } \\
\hline Fácies & \multicolumn{2}{|c|}{ Inequigranular } & \multicolumn{2}{|c}{ Enclave Básico } & \multicolumn{2}{c}{ Ortognaisses } \\
\hline Amostra & CP48 & CP101 & BP194 & BP195 & GP50 & GP53 \\
\hline SiO2 & 36,70 & 36,65 & 34,91 & 35,11 & 34,72 & 34,83 \\
\hline TiO2 & 2,75 & 4,34 & 3,29 & 2,54 & 5,06 & 5,45 \\
\hline Al2O3 & 15,58 & 14,21 & 13,55 & 14,60 & 13,40 & 13,47 \\
\hline Cr2O3 & 0,00 & 0,00 & 0,00 & 0,00 & 0,00 & 0,02 \\
\hline FeO & 20,96 & 20,45 & 32,08 & 29,96 & 30,02 & 29,28 \\
\hline MnO & 0,32 & 0,32 & 0,50 & 0,12 & 0,20 & 0,29 \\
\hline MgO & 10,01 & 10,79 & 2,73 & 2,95 & 4,72 & 4,45 \\
\hline CaO & 0,00 & 0,17 & 0,00 & 0,00 & 0,02 & 0,01 \\
\hline Na2O & 0,00 & 0,13 & 0,00 & 0,00 & 0,00 & 0,00 \\
\hline K2O & 9,79 & 9,36 & 9,64 & 9,28 & 9,63 & 9,79 \\
\hline F & 0,00 & 0,09 & 0,30 & 0,04 & 0,26 & 0,00 \\
\hline Cl & 0,03 & 0,05 & 0,31 & 0,34 & 0,07 & 0,10 \\
\hline Total & 96,17 & 96,60 & 97,35 & 94,97 & 98,14 & 97,73 \\
\hline & $F 0740$ \\
\hline
\end{tabular}

\begin{tabular}{l|c|c|c|c|c|c} 
& \multicolumn{4}{|c}{ Fórmula estrutural na base de 23 átomos de oxigênios } \\
\hline Si & 5,60 & 5,57 & 5,63 & 5,70 & 5,48 & 5,49 \\
\hline AlIV & 2,39 & 2,42 & 2,36 & 2,29 & 2,49 & 2,50 \\
\hline SomaZ & 8,00 & 8,00 & 8,00 & 8,00 & 7,98 & 8,00 \\
\hline AlVI & 0,40 & 0,11 & 0,21 & 0,50 & 0,00 & 0,00 \\
\hline Ti & 0,31 & 0,49 & 0,40 & 0,31 & 0,60 & 0,64 \\
\hline $\mathbf{C r}$ & 0,00 & 0,00 & 0,00 & 0,00 & 0,00 & 0,00 \\
\hline Fe2t & 2,67 & 2,60 & 4,33 & 4,07 & 3,96 & 3,86 \\
\hline Mn & 0,04 & 0,04 & 0,06 & 0,01 & 0,02 & 0,04 \\
\hline Mg & 2,27 & 2,44 & 0,65 & 0,71 & 1,11 & 1,04 \\
\hline SomaY & 5,72 & 5,70 & 5,67 & 5,62 & 5,70 & 5,61 \\
\hline Ca & 0,00 & 0,02 & 0,00 & 0,00 & 0,00 & 0,00 \\
\hline Na & 0,00 & 0,04 & 0,00 & 0,00 & 0,00 & 0,00 \\
\hline K & 1,90 & 1,81 & 1,98 & 1,92 & 1,94 & 1,97 \\
\hline SomaX & 1,90 & 1,88 & 1,98 & 1,92 & 1,94 & 1,97 \\
\hline Total & 15,63 & 15,58 & 15,66 & 15,54 & 15,63 & 15,58 \\
\hline $\mathbf{F}$ & 0,00 & 0,04 & 0,15 & 0,02 & 0,13 & 0,00 \\
\hline $\mathbf{C l}$ & 0,008 & 0,01 & 0,08 & 0,09 & 0,02 & 0,02 \\
\hline $\mathbf{M g /}$ & 0,46 & 0,48 & 0,13 & 0,15 & 0,22 & 0,21 \\
\hline Ag+Fe & 2,80 & 2,54 & 2,57 & 2,79 & 2,49 & 2,50 \\
\hline
\end{tabular}

$\mathrm{R}^{3+}\left(\mathrm{Al}^{\mathrm{VI}}+\mathrm{Ti}+\mathrm{Cr}\right)$ (Fig. 4B), de acordo com a seguinte equação:

$$
\mathrm{Si}^{\mathrm{IV}}+\mathrm{R}^{2+}=\mathrm{Al}^{\mathrm{IV}}+\mathrm{R}^{3+}
$$

A análise individual dos gráficos de substituição $\mathrm{R}^{2+} v s$. componentes de $\mathrm{R}^{3+}$ indica que o $\mathrm{Al}^{\mathrm{IV}}$ é o principal responsável por este tipo de substituição, embora o Ti apresente também considerável participação, sobretudo para as amostras das Fácies Porfirítica e Foliada do MGA.

O teste de outros elementos individualmente como $\mathrm{R}^{2+} v s$. $\mathrm{Al}^{\mathrm{VI}}$, cujos diagramas não são aqui apresentados, mostra boa correlação negativa e indica a existência da substituição do $\mathrm{Al}^{\mathrm{VI}}$, na posição octaédrica, pelo $\mathrm{Fe}^{2+}$ e Mg. O Ti mostra também boa correlação linear com o $\mathrm{Mg}$.

Os diagramas $\mathrm{R}^{3+} v s$. componentes individuais de $\mathrm{R}^{2+}$ mostram participação do $\mathrm{Mg} \mathrm{e} \mathrm{Fe}^{2+}$ (Fig. 4B) neste tipo de substituição.

O diagrama $\mathrm{Ti}$ vs. $\mathrm{Mg}$ indica a existência de substituição somente para o grupo de biotita secundária, sugerindo que este tipo de substituição ocorreu somente associado à fase de deformação.

Outros tipos de substituições testadas para as biotitas dos MGA e MGG, cujos diagramas não são aqui apresentados, são do tipo talco $\left(\mathrm{Ca}+\mathrm{Al}^{\mathrm{IV}}\right.$ vs. $\mathrm{K}$ $+\mathrm{Si})$ e clitonita $\left(\mathrm{Si}+\mathrm{SV}\right.$ vs. $\left.\mathrm{K}+\mathrm{Al}^{\mathrm{IV}}\right)$, propostos por Hewitt \& Wones (1986), e mostram uma boa correlação linear negativa nesta última, sugerindo substituição no sítio tetraédrico da Si pelo $\mathrm{Al}^{\mathrm{IV}}$.

DISCUSSÃO E CONCLUSÕES Os dados de química mineral aqui apresentados, para as amostras dos Maciços Graníticos Arrozal (Fácies Porfirítica, Foliada e Leucogranítica, e enclave diorítico) e Getulândia (Fácies Inequigranular rosada e enclave diorítico), e rocha encaixante (ortognaisse), permitiram caracterizar a composição dos diferentes minerais analisados (feldspato alcalino, plagioclásio, biotita, anfibólio e piroxênio) e testar as possíveis substituições presentes nos cristais de biotita, assim como avaliar as modificações químicas promovidas pela deformação em estado sólido imposta ao Maciço Granítico Arrozal (Fácies Foliada).

Os plagioclásios estudados apresentam composição mais cálcica nos megacristais do que nos cristais da matriz, afirmando assim a importância do processo de cristalização fracionada durante sua cristalização. A existência no MGA de andesina de composição pouco mais básica $\left(\mathrm{Ca} 0\right.$, entre 6,3 a 7,7\%; $\mathrm{Na}_{2} 0$, entre 6,1 e $7,2 \%$ ) do que no MGG (Ca0, entre 6,3 a 6,9\%; $\mathrm{Na}_{2} 0$, entre 6,3 e $6,7 \%$ ) sugere um caráter magmático relativamente mais evoluído para estes últimos (Tab. 1). A presença de um grupo de plagioclásio mais empobrecido em Ca (entre 4,2 e 4,4\% em Ca0, contra 6,4 a 7,6\%) e $\mathrm{Al}\left(\sim 23,5 \%\right.$ em $\mathrm{Al}_{2} \mathrm{O}_{3}$, contra $\left.\sim 25,5 \%\right)$ na Fácies Foliada (MGA) se deve provavelmente a presença de uma fase fluída associada à deformação em estado sólido que promoveu a alteração de minerais originalmente magmáticos. Os teores mais baixos em $\mathrm{CaO}(\sim 4,5 \%)$ 
na Fácies Leucogranítica podem ser explicados também neste mesmo caminho. Por outro lado, os teores mais elevados em $\mathrm{CaO}(\sim 19 \%)$ e $\mathrm{Al}_{2} \mathrm{O}_{3}(\sim 36 \%)$ no plagioclásio do enclave do MGA do que na rocha hospedeira indica, na maioria dos casos, a ausência de equilíbrio químico entre os dois sistemas.

A ocorrência de ortoclásio como megacristal em rochas do MGA é indicativa de cristalização magmática precoce deste mineral, enquanto a ocorrência de microclina intersticial na matriz com fase tardi a (MGA) parece estar relacionada mais à deformação em estado sólido associada à movimentação da Zona de Cisalhamento de Além Paraíba, que teria afetado as rochas do maciço, após sua completa cristalização magmática.

A composição mais rica em ferro da biotita do MGA (Fe \# entre 0,6 e 0,7) do que do MGG (Fe \# $0,5$ e 0,6$)$ indica um caráter magmático mais evoluído para a primeira (Fig. 3A), com aquela situando-se entre os pólos da annita e siderofilita, enquanto esta situa-se mais entre os pólos da flogopita e eastonita. Grande parte das biotitas da Fácies Foliada apresenta composição semelhante à da Fácies Porfirítica (Fig. 3A; Tab. 2), sugerindo pouca influência da deformação na sua mudança composicional, devendo refletir uma composição muito próxima da composição do líquido que lhe deu origem. Por outro lado, um outro grupo de biotita que se mostra mais enriquecida em $\mathrm{Al}\left(\mathrm{Al}_{2} \mathrm{O}_{3}\right.$ entre 17,5 e $18,9 \%$, contra 13,9 a $14,2 \%$ ) e mais empobrecida em $\mathrm{MgO}$ (entre 6,6 e 8,1\%, contra 9,7 a 10\%) e $\mathrm{TiO}_{2}$ (entre 2,6 e $3,8 \%$, contra 4,8 e $5,8 \%$ ) sugere que as diferenças composicionais apresentadas por este grupo estão relacionadas a processos de deformação associados a fluidos que afetaram o MGA, o que é confirmado pelos dados petrográficos. Do conjunto de Fácies do MGA, a biotita da Fácies Leucogranítica é a que apresenta caráter mais evoluído (Fig. 3A; Tab. 2).

A superposição entre as biotitas do MGG e as do MGA (Fácies Porfirítica e Foliada) nos diagramas discriminantes (Chevremont et al. 1988, Abdel-Rahman 1994) aponta para uma forte vinculação genética entre os magmas que deram origem a estas biotitas, assim como sugere cristalização magmática sob condições similares (Fig. 3E e 4C). A Fácies Leucogranítica apresenta comportamento diferente em um dos diagramas (Chevremont et al. 1988) e semelhante em outro apenas para um grupo de biotita (Abdel-Rahman 1994), confirmando assim as diferenças composicionais desta Fácies já apontadas pelo quimismo dos outros minerais.

As diferenças químicas entre as biotitas do enclave do MGA (17,4\% em MgO, contra 6,7 a 7,5\%; $12,7 \%$ em FeO, contra 23\%) e as da rocha hospedeira (amostra FP, da Fácies Porfirítica) (Tab. 2) indicam que não foi atingido o equilíbrio químico entre os dois sistemas, reforçando desta forma o que já foi observado na composição do plagioclásio.

O comportamento semelhante nos diagramas de substituição entre a biotita da Fácies Foliada com a da Fácies Porfirítica reflete a predominância de substituições de natureza magmática nas mesmas, sugerindo que a deformação imposta no estado sólido às rochas do MGA não foi suficientemente intensa para alterar de forma significativa estas substituições.

Os anfibólios dos MGA e MGG apresentam parâmetros químicos semelhantes. As pequenas variações composicionais apresentadas podem ser relacionadas aos diferentes estágios evolutivos de cada maciço.

Ressalta-se a presença de ilmenita associada com apatita e mica branca no MGA, que denotam um caráter mais peraluminoso a este maciço, enquanto a ocorrência de titanita, allanita e magnetita no MGG refletem num caráter metaluminoso.

Agradecimentos Os autores agradecem à FAPESP (Proc. 98/00912-8), pelo suporte financeiro que permitiu a realização das atividades de campo e da parte analítica do trabalho, e ao CNPq (Proc. 300423/82-9, de R, Machado), pela concessão de uma bolsa de Produtividade em Pesquisa.

\section{Referências}

Abdel-Rahmam A. M. 1994. Nature of biotites from alkaline, calc-alkaline and peraluminous magmas. J. Petrol., 35 (2):525-541.

Batista J.J. 1984. Caracterização dos processos geológicos evolutivos precambrianos na região de São Fidélis, norte do Estado do Rio de Janeiro. Tese de Doutoramento, Instituto de Geociências, Universidade de São Paulo, $123 \mathrm{p}$

Batista J.J. \& Kawashita K. 1985. Contribuição ao acervo geocronológico da porção setentrional do cinturão Ribeira .In: SBG, Simp. Reg. Geol., 5, São Paulo, 1985. Atas, vol.1, p.187-200.

Caddah L.F.G. Santos J.R.S.B., Valença J.G., Pires F.R.M. 1987 - Granitóides da Serra da Misericórdia (RJ): sucessão estratigráfica, posicionamento, forma e origem. In: SBG/RJ-ES Simp. Geol., Rio de Janeiro, Anais, vol.1,
132-146.

Chevremont P.O., Gagny C. O., La Roche H., Pupin J. P., Rossi P. 1988. Representation cartographique du plutonisme acide et du plutonisme intermédiaire associé. Documents du BRGM, n 152, 61p.

Cordani U.G. \& Teixeira W. 1979. Comentários sobre as determinações geocronológicas existentes para as regiões das folhas Rio de Janeiro, Vitória e Iguape. Texto Explicativo da Carta Geológica ao Milionésimo, folhas Rio de Janeiro (SF-23), Vitória (SF-24) e Iguape (SG-23). Brasília, DNPM, p. 175-207.

Cordani U.G., Delhal J., Gomes C.B., Ledent D. 1968. Nota preliminar sobre idades radiométrica em rochas da região da Serra do Orgãos e vizinhanças (Leste de Minas Gerais e Estado do Rio de Janeiro). Bol. Soc. Bras., São Paulo, 17(1):89-92. 
Cordani U.G., Delhal J., Ledent D.1973. Orogénèses superposées dans le Pré-Cambrian du Brésil Sud-Oriental (États de Riode Janeiro et de Minas Gerais). Rev. Bras. Geoc., 3(1):1-22.

Deer W.A., Howie R.A., Zussman J. 1973. Rocks forming minerals. London, Longman Ed., 5 vol.

Deer W.A., Howie R.A., Zussman J. 1982. Rocks forming minerals.Vol 1 A Orthosilicates, London, Longman Ed, $668 \mathrm{p}$.

Delhal J., Ledent D., Cordani U.G. 1969 - Ages U/Pb, Rb/Sr et $\mathrm{K} / \mathrm{Ar}$ de formations métamorphiques et granitiques du Sud-Est du Brésil (États de Rio de Janeiro et de Minas Gerais). Ann. Soc. Géol. Belg., 92:271-283.

Dias Neto C.M., Tassinari, C.G., Egydio-Silva, M. 1995. Idades $\mathrm{Rb}-\mathrm{Sr}$ das rochas da região de Bananal-SP. Boletim do IG-USP, Série Cient., 26:59-68.

Dymek R.F., Boak J.L., Kerr, M.T. 1983. Green micas in the archean Isur and Malene supracrustal rocks, southern west Greenland, and the occurrence of a barian-chromian muscovite. Rapport Gronlands Geolliske Undersoegelse, 111:71-82.

Figueiredo M.C.H. \& Campos Neto M.C. 1993. Geochemistry of the Rio Doce magmatic arc, Southeastern Brazil. An. Acad. Bras. Ciênc., 65 (Supl.1):63-81.

Fonseca A.C. 1986. Geocronologia das rochas graníticas e suas encaixantes na cidade do Rio de Janeiro. São Paulo, Dissertação de Mestrado, Instituto de Geociências, Universidade de São Paulo, 281p.

Fonseca A.C., Cordani U.G., Kawashita K. 1984. Dados preliminares sobre a Geocronologia das rochas graníticas e suas encaixantes na cidade do Rio de Janeiro- Método Rb/Sr. In: SBG, Congr. Bras.Geol., 33, Rio de Janeiro, Anais, 5: 2333-2345.

Fonseca M.J.G., Silva Z.C.G., Campos D.A., Tosatto P. 1979. Texto Explicativo da Carta Geológica do Brasil ao Milionésimo, folhas Rio de Janeiro (SF23), Vitória (SF-24) e Iguape (SG-23). Brasília, DNPM, 240p.

Heilbron M. 1995. O segmento central da Faixa Ribeira: síntese geológica e ensaio de evolução geotectônica. Tese de Livre Docência, Departamento de Geologia e Geofísica, Universidade Estadual do Rio de Janeiro, 110p.

Heilbron M., Valeriano C.M., Valladares C.S., Machado N. 1995. A orogênese brasiliana no segmento central da Faixa Ribeira, Brasil. Rev. Bras. Geoc., 25(4):249-266.

Hembold R. 1967. Resumo da geologia do Estado da Guanabara, acompanhando o mapa geológico 1: 50.000. Relatório da Comissão de Especialista do CNPq, sobre Movimentos de encosta no estado da Guanabara e regiões circundantes. Rio de Janeiro, apêndice $n^{0}$ 5, p. 31-34.

Hembold R., Valença J.G., Leonardos Jr., O.H.1965. Mapa Geológico do Estado da Guanabara. DNPM/MME, escala 1: 50.000 .

Hewitt D. A. \& Wones D.R. 1986. Experimental phase relations of the micas. In: S.W. Bailey (ed.), Micas: Reviews in Mineralogie. Mineral. Soc. Amer., vol. 13, p.201-297.

Higgins W. M. 1971. Cataclastic rocks. U.S. Geol. Survey, Prof. Paper, 687, 77p.

Hippertt J.F.M. 1990. Contribuição à geologia e petrologia dos “augen” gnaisses de Niterói, RJ. São Paulo, Disser- tação de Mestrado, Instituto de Geociências, Universidade de São Paulo, 203p.

Junho M.C.B., Weber-Difenbach K., Wiedemann C., Penha H.M. 1987. Major and minor elements geochemistry of Pedra Branca, Frades and Nova Friburgo granitic complexes, Ribeira Mobile Belt, RJ, Brazil. Rev. Bras. Geoc., 17:507-511.

Junho M.C.B. 1991. Contribuição à Petrologia dos maciços graníticos da Pedra Branca, Frades e Nova Friburgo, Rio de Janeiro. Tese de Doutoramento, Instituto de Geociências, Universidade Federal do Rio de Janeiro, 198p.

Junho M.C.B. 1993. Granitóides brasilianos da região central do Estado do Rio de Janeiro - geoquímica preliminar. An. Acad. Bras. Ciênc., 65:161-179.

Junho M. C. B. 1998. Rochas granitóides do estado do Rio de Janeiro. In: M.J.G. Fonseca (Coord.). Mapa geológico do Estado do Rio de Janeiro, escala 1:400.000. Rio de Janeiro, DNPM/MME, 141p. (Texto Explicativo).

Junho M.C.B. 1982. Geologia, petrografia e geoquímica preliminar do granito de Teresópolis, RJ. Rio de Janeiro, Dissertação de Mestrado, Instituto de Geociências/ UFRJ 198p.

Junho M. C. B. \& Penha, H.M. 1985. Geologia e geoquímica dos granitos de Teresópolis, RJ. An. Acad. Bras. Ciênc., 57:546.

Junho M. C. B. \& Wiedemann C. 1987. Petrografia comparativa de três complexos intrusivos da província granítica do Estado do Rio de Janeiro. In: Simp. Geol. Reg., Núcleo SBG-RJ/ES, Anais, p.120-131.

Ledent D. \& Pasteels P. 1968. Déterminations de l'âge des roches post-tectoniques du sud-est du Brésil. Ann. Soc. Géol. Belg. 91:305-309.

Leonardos Jr., O.H. 1973. The origin and alteration of granitic rocks in Brazil: a study of metamorphism, anatexis, weathering and fertility within granitic terrains in eastern Brazil. PhD. England, Thesis, University of Manchester, $183 \mathrm{p}$.

Machado Filho L., Ribeiro M.W., Gonzales S.R., Schemini C.A., Santo Neto A., Palmeira R.C.B., Pires J.L., Teixeira W., Castro H.E. 1983. Folhas Rio de Janeiro/Vitória (SF-23/24) (Levantamento de Recursos Naturais). Projeto RADAMBRASIL, vol 32, p.29-304.

Machado N., Valladares C., Heilbron M., Valeriano C. 1996. $\mathrm{U} / \mathrm{Pb}$ geochronology of the central Ribeira belt: implications for the evolution of brasiliano orogeny. Prec. Res., 79:347-361.

Machado R. 1997. Litogeoquímica e tectônica dos granitóides neoproterozóicos do Cinturão Paraíba do Sul no Estado do Rio de Janeiro. Tese de Livre-Docência, Instituto de Geociências, Universidade de São Paulo, 215p.

Machado R. \& Pellogia A.U.G. 1987. Mapa de distribuição das rochas granitóides do Estado do Rio de Janeiro: uma avaliação preliminar das informações disponíveis. In: SBG/Núcleo SP, Simp. Reg. Geol., 4, Rio Claro, Atas, v.1, p.93-96.

Machado R. \& Dehler N.M. 2002. Revisão e discussão do significado tectônico dos granitóides do tipo-S no estado do Rio de Janeiro. Rev. Bras. Geoc., 32(4):471-480.

Machado R. \& Demange M. 1991. Contexto tectônico e estrutural dos granitóides brasilianos do Estado do Rio de 
Janeiro. In: SBG/Núcleo SP, SNET, 3, Bol. Res. Exp., Rio Claro, p.64-65.

Machado R. \& Demange M. 1992. Granitogênese brasiliana no Estado do Rio de Janeiro: Caracterização geoquímica, modelo tectônico e considerações geológicas sobre o embasamento e a cobertura do cinturão Ribeira na região. In: SBG,/Núcleo SP, Congr. Bras. de Geol., 37, São Paulo, Bol. Res. Exp., v. 1, p. 379-380.

Machado R., Demange M., Monteiro R.L. 1989. Granitóides do Estado do Rio de Janeiro: nível estrutural de colocação e suas relações com as fases de deformação e com o grau de metamorfismo. In: SBG RJ/SP, Simpósio de Geologia do Sudeste, 1, Rio de Janeiro, Boletim de Resumos, p.145-146.

Machado R. \& Demange M. 1994. Classificação estrutural e tectônica dos granitóides neoproterozóicos do Cinturão Paraíba do Sul no Estado do Rio de Janeiro. Boletim do IG-USP, 25:81-96.

Machado R., Demange M.,Viallete Y. 1996. Idades geocronológicas $\mathrm{Rb} / \mathrm{Sr}$ da granitogênese brasiliana no segmento setentrional da faixa Ribeira, Estado do Rio de Janeiro. In: SBG/Núcleo BA/SE, Congr. Bras. Geol., 39, Salvador, v.1, p.8-40.

Nummer A. R. 2001. Geometria e cinemática de alojamento do maciço granítico Arrozal, sudoeste do Estado do Rio de Janeiro. Tese de Doutoramento, Instituto de Geociências, Universidade de São Paulo, 169p.

Nachit H., Razafimahefa N., Stussi J.M., Carron J.P. 1985. Composition chimique des biotites et typologie magmatique des granitóides. C.R. Acad. Sci., Paris, 301(II):813818.

Penha H.M. 1984. Granitóides da região central do Estado do Rio de Janeiro: uma síntese dos conhecimentos existentes. In: SBG/Núcleo RJ/ES, Congr. Bras. Geol., 33, Rio de Janeiro, Anais, v. 6, p. 2849-2853.

Penha H.M. \& Wiedemann C.M. 1984. Granitóides da região central do Estado do Rio de Janeiro. In: SBG/ Núcleo RJ, Congr. Bras. Geol., 33, Rio de Janeiro, Roteiro de Excursões, p.5433-5456.

Penha H.M., Ferrari A.L., Ribeiro A., Amador E.S., Pentagna F.V.P., Junho M.C.B., Brenner T.L. 1980. A Geologia da Folha Petrópolis. In: SBG, Congr. Bras. Geol., 31, Balneário Camboriú, Anais, vol.5, p.2965-2974.

Pereira R.M., Moura C.A.V., Junho M.C.B. 2002. Single zircon $\mathrm{Pb}$-evaporation age of some granitic plutons in the Central part of the Ribeira Belt, southerstern Brazil. Rev. Bras. Geoc., 17(3):327-334.
Pires R.M., Valença J.G., Ribeiro A. 1982. Multistage generation of granite in Rio de Janeiro, Brazil. An. Acad. Bras. Ciênc. 54(3):563-574.

Porto Jr., R. Duarte B.P., Valente S.C. 1992. Processos de diferenciação magmática atuantes na formação da Fácies hololeucocrática do granito Pedra Branca, maciço da Pedra Branca, Rio de Janeiro, RJ. In: SBG, Congr. Bras. Geol., 38, Natal, Anais, vol. 6, p.2744-2754.

Puget A.J.F. \& Penha H.M. 1980. Granitos da região de Ipiranga, Magé, RJ - considerações geoquímicas e petrológicas. In: SBG, Congr. Bras. Geologia, 31., Camboriú, Anais, Camboriú, SBG, v. 4, p. 2215-2229.

Siga Jr. O., Teixeira, W., Cordani U.G., Kawashita K., Delhal J. 1982. Padrão geológico-geocronológico das rochas de alto grau da parte setentrional da Faixa Ribeira, a norte do Rio de Janeiro, Brasil. In: Congr. Lat. Geol. 5, Buenos Aires, Actas, vol.1, p.349-370.

Silva L.C., McNaughton N.J., Hartmann L.A., Fletcher I.R. 2003. Zircon U-Pb SHRIMP dating of the Serra dos Órgãos and Rio de Janeiro gneissic granitic suites: implications for the (560 Ma) Brasiliano/Pan-African collage. Rev. Bras. Geoc., 33(2):237-244.

Tupinambá M. 1999. Evolução tectônica e magmática da Faixa Ribeira na região serrana do estado do Rio de Janeiro. Tese de Doutoramento, Instituto de Geociências, Universidade de São Paulo, 221p.

Valladares C.S. 1996. Evolução geológica do complexo Paraiba do Sul, no segmento central da Faixa Ribeira, com base em estudos de geoquímica e geocronologia $U-P b$. Tese de Doutoramento, Instituto de Geociências, Universidade de São Paulo, 147p.

Zorita M.E. \& Penha H.M. 1980. Geoquímica das rochas graníticas da região de Suruí, Magé, RJ. In: SBG, Congr. Bras. Geol., 31, Balneário de Camboriú, Anais, v. 4, p. 2391-2399.

Wiedemann C.M. 1993. The evolution of the Paleozoic, lateto post-collisional magmatic arc of the coastal mobile belt, in the state of Espírito Santo, eastern Brazil. An. Acad. Bras. Ciênc. 65 (Supl.1):163-181.

Wiedemann C.M., Penha H.M, Schmidt-Thome R. 1987. Granitóides do Espírito Santo and Rio de Janeiro States. Rev. Bras. Geoc. 17(4):674-689.

\section{Manuscrito A-1646 Aceito em 13 de junho de 2007}

